\title{
Development and Characterization of Antimicrobial Packaging Films
}

\section{Zinash Assefa ${ }^{1}$ and Shimelis Admassu ${ }^{2 *}$}

${ }^{1}$ Addis Ababa Science and Technology Institute, Addis Ababa, Ethiopia

${ }^{2}$ Addis Ababa University, Food Engineering Graduate Program, School of Chemical and Bio- Engineering, Addis Ababa Institute of Technology, Private mail bag: 33381, Addis Ababa, Ethiopia

\begin{abstract}
The purpose of this work was to develop and study the effect of bioactive component towards the inhibition of microbial activities of films; aiming to assess their performance in employing for antimicrobial packaging film. In order to achieve appropriate inhibition effect of the antimicrobial agent, the structure of the films was changed from a highly asymmetric and porous to the dense by the modulation of the composition of the initial casting solution. The results on inhibition effect of starch-based films prepared from $90-100 \%(\mathrm{w} / \mathrm{w})$ starch and $0-10 \%(\mathrm{w} / \mathrm{w})$ bioactive component (saponin) revealed antimicrobial activity in a growth of bacteria (Escherichia coli, Salmonella typhi and Entrobacter erogenous). An increase in saponins concentration in the casting solution decreased the growth of microorganisms and the inhibition activities of the films increased. Results on moisture content, transparency, swelling, solubility and mechanical properties of the films at different concentrations of bioactive component and levels of film thickness reveled significance differences at $p<0.05$. The film with $10 \%$ saponins concentration showed better inhibition effect in a growth of Salmonella typhi, E. erogenous and E. coli for 0.02 and $0.04 \mathrm{~mm}$ film thickness. The maximum antimicrobial activities and tensile strength of the films increased with an increase in an amount of the bioactive component in the casting solution. In conclusion, this study confirms that the saponins extracted from haricot bean seeds and incorporated in the films had antibacterial activity on pathogenic bacteria. The films may be used for food packaging that are extremely vulnerable to microbial growth or directly used as a surface coating on perishable fruits and vegetables consecutively to augment their microbial safety and extend shelf stability of food products. Undoubtedly, this area of research holds considerable potential on food delivery systems.
\end{abstract}

Keywords: Antimicrobial activity; Bioactive component; Mechanical properties; Inhibition effect; Pathogenic bacteria; Packaging films

\section{Introduction}

The packaging system that is able to kill or inhibit spoilage and pathogenic microorganisms that are contaminating foods is categorized as antimicrobial packaging. It is particularly designed to control growth of microorganisms; unlike conventional food packaging systems which are used for shelf-life extension, quality maintenance, and safety assurance which could be achieved by various methods [1]. A safe and reliable delivery of food has emerged as one of the major industrial concerns of this time that affects both the developing and western world. Surprisingly, some $30 \%$ of food losses in developing countries are the direct result of improper food packaging and failed logistics. The global challenge of food delivery has thus forced recognition of the importance of materials used for food packaging.

Antimicrobial packaging materials are food preservation systems with antimicrobial attributes that involve more than basic barrier properties. These attributes can be achieved by incorporating microbialcidal or microbialstatic agents into such a packaging system, or by using active antimicrobial polymeric materials. The introduction of antimicrobial agents into food packaging material helps to extend the shelf-life of food products by inhibiting the growth of microorganism. Antimicrobial packaging systems can extend the lag period and reduce the growth rate of microorganisms, prolonging a product's shelf stability and promote safety [2].

In order to prepare antimicrobial films, different synthetic antimicrobial chemicals have been incorporated into packaging materials, including organic or inorganic acids, metals, alcohols, ammonium compounds or amines. However, the increasing consumer health concern and growing demand for healthy foods have stimulated the use of natural bio-preservatives, for instance antimicrobial enzymes and compounds like starch [3]. Natural food antimicrobial films can slow down or inactivate spoilage and pathogenic microorganisms; and these functions has increased importance in recent past years to improve food safety.

Packaging materials can be manufactured from different materials, out of which starch becomes one of them due to its biodegradability and availability. Starch is a complex carbohydrate which is insoluble in water. It is usually extracted from cereal seeds (corn, wheat, and rice), roots and tubers (potato, taro, tapioca) [4]. Starch has been widely used as a raw material in film production, because of increasing prices and decreasing availability of conventional film-forming resins. It is also useful for making films because it degrades into harmless products when placed in contact with soil microorganisms [5].

Taro starch is biodegradable and the small size of taro starch granules (about one-tenth of size of maize starch granules) makes them superior to other starches for the production of biodegradable packaging materials which is an important requirement in agroindustrial waste management [6]. A chemical structure of a simple starch is presented in the mechanism of how the antimicrobial packaging inhibits the microbial growth. A microorganism will first try to hydrolyze the starch-based particles, causing the release of the

*Corresponding author: Shimelis Admassu, Addis Ababa University, Food Engineering Graduate Program, School of Chemical and Bio- Engineering, Addis Ababa Institute of Technology, Private mail bag: 33381, Addis Ababa, Ethiopia, E-mail: shimelisemire@yahoo.com

Received February 17, 2013; Accepted May 02, 2013; Published May 10, 2013

Citation: Assefa Z, Admassu S (2013) Development and Characterization of Antimicrobial Packaging Films. J Food Process Technol 4: 235. doi:10.4172/2157 7110.1000235

Copyright: ( 2013 Assefa Z, et al. This is an open-access article distributed under the terms of the Creative Commons Attribution License, which permits unrestricted use, distribution, and reproduction in any medium, provided the original author and source are credited. 
antimicrobial compounds. The compounds inhibit the microbial growth because they are capable of either destroying or inhibiting the growth of microscopic and submicroscopic organisms [7].

A starch-based film is considered an economical material for packaging and, therefore, this study aimed at the development of food packaging based on taro starch. The disadvantages of using starch are its brittleness and a relatively fast retrogradation. These disadvantages can be overcome by substituting part of the water in the starch by a highly viscous lubricant with low volatility. Addition of such a lubricant decreases the friction between the molecules and, therefore, lowers the glass transition temperature, which marks the transition between brittle and ductile. From the two most promising polyoles, sorbitol and glycerol, the latter appeared to give by far the best results [8].

In this study a starch-based film was prepared and incorporated with an antimicrobial agent (saponins) as a chelating agent. Saponins have been widely used in food and other industrial application; mainly as surface active and foaming agents [9]. The function of films is to inhibit or reduce the migration of moisture, oxygen, carbon dioxide, lipids and aromas, amongst others, since they provide semipermeable barriers. In addition they can transport food additives such as antioxidants, antimicrobial agents and flavors and/or improve the mechanical integrity and/or handling characteristics of the food $[10,11]$.

Contamination of food products by pathogenic bacteria (Listeria monocytogenes, Bacillus cereus, Escherichia coli (O157:H7)) has emerged as a serious public concern are identified as the most potent pathogens associated with food borne illnesses. Antimicrobial packaging is one promising approach to prevent both contamination of pathogens and growth of spoilage microorganisms on the surface of food [4]. Therefore, the use of agricultural biopolymers that are easily biodegradable and environmental friendly plays a significant potential role in the food supply chain together with surplus farm production.

The macromolecules must be dispersed or dissolved in a solvent in order to form a film and a plasticizer must be added to obtain the filmogenic solution. The process is completed by evaporation of the solvent or drying [12]. The macromolecules most used in the elaboration of starch-based films are proteins, polysaccharides (starch and starch derivatives, pectin, cellulose and cellulose derivatives, alginate and carrageenan) and lipids or a combination of these [13]. Plasticizers are defined as substances with high melting points, which, when added to another material cause changes in the physical, chemical and mechanical properties of the material [14]. Plasticizers result in an increase in flexibility of the polymer chains and an increase in mechanical resistance, decreasing possible discontinuities and brittle zones [10], in addition to improving the adhesiveness of the film [15].

The aim of the present study was to develop antimicrobial packaging films and characterize the effect of bioactive component on its antimicrobial activity against food pathogenic bacteria (Escherichia coli, Salmonella typhi and Entrobacter erogenous) and evaluate the physicochemical and mechanical properties of the starch-based packaging films.

\section{Materials and Methods}

\section{Material collection and sample preparation}

Taro which was used as a source of starch in this study was brought from Areca agricultural research center. Haricot bean varieties
(Phaseolus vulgaris L.), Beshbesh variety used in this study as a bioactive component source was brought from Melkassa Agricultural Research Center of Ethiopian Agricultural Research Institute. Both raw materials taro and haricot bean were packed with plastic bags and transported to Addis Ababa University Food Process Engineering laboratory. Taro was treated before extraction by removing all the soils and the foreign matters by washing and the entire damaged taro was discarded and the reaming clean sample was stored. Shimelis [16] reported that among many roles have been attributed to saponins, and it has been suggested that saponins play a protective role against insect, fungi and pathogenic bacteria attacks in the field and under storage conditions. The research report concluded that, the presence of a high concentration of saponins in the Beshbesh variety verifies a correlation with its resistance to disease. Beshbesh was selected among bean varieties due to its high concentration of sponins which in turn plays a protective role against bacteria. Hence, haricot bean (Beshbesh variety) was used as saponins source in starch-based film formulation. Haricot bean sample was prepared by removing all the foreign matters from it and stored at room temperature. Glycerol and Muller Hinton agar were purchased from local chemical supplier (Neway Plc, Addis Ababa).

\section{Production of taro starch}

Production of taro starch was undertaken according to the procedure described by Tomoko Naofumi [17]. The raw taro washed with water to take out different materials together with soil and remaining muscle. The washed taro then sliced in to small pieces and suspended in 10 -fold of $0.1 \% \mathrm{NaOH}$ aqueous solution for $48 \mathrm{hrs}$ at $5^{\circ} \mathrm{C}$. Starch granules separated by centrifuge at $3500 \mathrm{xG}$ for $15 \mathrm{~min}$ and the starch sample were neutralized with $\mathrm{HCl}$, followed by sieving through 200-mesh. Finally, the starch was dried using an air oven at $35^{\circ} \mathrm{C}$, ground, sieved using a $250 \mu \mathrm{m}$ sieve and stored in an air tight container under dry conditions. The proximate chemical composition of raw taro was determined using AOAC [18].

\section{Extraction of total saponins}

Extraction of saponins from haricot bean was carried out according to Zohar et al. [19]. Prior to all extractions; the haricot bean was grounded in a Wiley mill to pass $2-\mathrm{mm}$ pore-size screen. The powder was dried at $55^{\circ} \mathrm{C}$ for $72 \mathrm{hr}$ and next used for extraction of saponins in a soxhlet apparatus. The extraction was done with hexane for $6 \mathrm{hr}$ to remove all fats. The defatted powder (about $10 \mathrm{~g}$ ) was treated with hexane $(150 \mathrm{ml})$ for $3 \mathrm{hr}$. After cooling to a room temperature, the extract was collected and kept at $-20^{\circ} \mathrm{C}$ for starch-based film development and further analysis.

\section{Preparation of starch-based films}

In order to make antimicrobial starch-based film the procedure was adapted from the method describe by Eraricar Salleh et al. [20]. A film forming dispersion was prepared using about one gram of starch and $10 \mathrm{ml}$ distilled water. It was stirred for $60 \mathrm{~min}$ and then dispersion was gelatinized in a shaker water bath at $78-80^{\circ} \mathrm{C}$ for $10 \mathrm{~min}$. Glycerol was added as plasticizer to reach a concentration of about 0.3 $\mathrm{g}$ glycerol/g starch. Then $5 \mathrm{ml}$ of starch solution, while still hot, mixture was transferred into petri dishes of $100 \mathrm{~mm}$ diameter and $15 \mathrm{~mm}$ deep. The dishes were placed for $24 \mathrm{hrs}$ in an oven set at $95^{\circ} \mathrm{C}$. Subsequently the dishes were removed from the oven and the films were peeled off. Starch based films have been prepared under aseptic condition in microbiology laboratory. In order to evaluate the biological activity of saponins, its mixing ration with starch varies from 0-10 g (Table 1). 


\begin{tabular}{|c|c|c|c|}
\hline & \multicolumn{3}{|c|}{ Parameters } \\
\hline Sample code & Starch (\%) & Saponins (\%) & Thickness of the film(mm) \\
\hline Control & 100 & 0 & 0.02 \\
\hline $\mathrm{Sf}_{1}$ & 98 & 2 & 0.02 \\
\hline $\mathrm{Sf}_{2}$ & 96 & 4 & 0.02 \\
\hline $\mathrm{Sf}_{3}$ & 94 & 6 & 0.02 \\
\hline $\mathrm{Sf}_{4}$ & 92 & 8 & 0.02 \\
\hline $\mathrm{Sf}_{5}$ & 90 & 10 & 0.02 \\
\hline $\mathrm{Control}_{2}$ & 100 & 0 & 0.04 \\
\hline $\mathrm{Sf}_{6}$ & 98 & 2 & 0.04 \\
\hline $\mathrm{Sf}_{7}$ & 96 & 4 & 0.04 \\
\hline $\mathrm{Sf}_{8}$ & 96 & 6 & 0.04 \\
\hline $\mathrm{Sf}_{9}$ & 92 & 8 & 0.04 \\
\hline $\mathrm{Sf}_{10}$ & 90 & 10 & 0.04 \\
\hline & Table 1: Mixing ratio of starch and saponins. \\
\hline
\end{tabular}

\section{Analytical methods}

\section{Evaluation of physicochemical properties of starch-based films}

Pasting clarity: The pasting clarity of taro starch was determined according to Ashveen et al. [21]. Starch samples were suspended in distilled water in screw cap tubes. $\mathrm{pH}$ of the slurries were adjusted to acidic, basic, and neutral by the addition of $0.1 \mathrm{M} \mathrm{HCl}$ or $\mathrm{NaOH}$ as required. The tubes were then heated in a boiling water bath (with occasional shaking) for $30 \mathrm{~min}$. After cooling to ambient temperature, the percentage transmittance $(\% \mathrm{~T})$ at $650 \mathrm{~nm}$ was determined against water as a blank using a spectrophotometer.

Solubility and swelling power of starch: The solubility and swelling power of the starch were determined according to the method adapted from Feroz and Abid [22] as, one gram of starch transferred in to dried test tube and weighed $\left(\mathrm{W}_{1}\right)$ then with in $50 \mathrm{ml}$ of distilled water. The starch was heated at $40,50,60$ and $70^{\circ} \mathrm{C}$ for $1 \mathrm{~h}$ while gently stirring and by rapid cooling to room temperature then centrifuged at 3,500 rpm for $30 \mathrm{~min}$. Then five $\mathrm{ml}$ of the supernatant was dried to a constant weight at $120^{\circ} \mathrm{C}$. The residue obtained after drying the supernatant represented the amount of starch solubilized in water. The solubility of starch was calculated in percent. The residue obtained from the experiment after centrifugation with water was transferred to a clean, dried test tube and reweighed $\left(\mathrm{W}_{2}\right)$ and the percentage swelling was calculated as:

$$
\text { Swelling power of } \operatorname{starch}(\%)=\frac{W_{2}-W_{1}}{W_{1}} \times 100
$$

Where: $\mathrm{W}_{1}$-Starch in dried test tube and $\mathrm{W}_{2}$ - Residue after centrifugation

Starch-based film moisture content: The moisture content was determined according to the method proposed by Finkenstadt and Willet [23]. The sample was heated for $25 \mathrm{~min}$ at $110^{\circ} \mathrm{C}$. The experiment of moisture content was performed in 3 replicates and the average was then recorded. The moisture content (MC) of the starch-based film was determined gravimetrically using equation, 2 :

$$
M C=\frac{M_{f}-M_{i}}{M_{i}} \times 100
$$

Where: MC-Moisture content of the starch-based film,

$M_{f}$ is the final moisture content of the starch-based film and

$M_{i}$ is the initial moisture content of the starch-based film.

Transparency of the starch-based film: The transparency of films was determined using UV spectrophotometer according to the method described by Bourtoom and Chinnah [24]. The film samples were cut into rectangles and placed on the internal side of the spectrophotometer cell. The transmittance of the films was determined at $600 \mathrm{~nm}$. The transparency was calculated as follows:

$$
\text { Transparency }=\frac{-\log T 600}{X}
$$

Where-T600 is the transmittance at $600 \mathrm{~nm}$ and $\mathrm{X}$ is the film thickness (mm).

Swelling of films: The water sorption capacity of the starch films was evaluated based on the method described by Bourtoom and Chinnah [24] through soaking the films in a phosphate buffered saline (PBS at $\mathrm{pH}$ 7.4) at room temperature. A known weight of the film was placed in the PBS media for 30 minutes. The starch film was blotting with a filter paper to remove the excess water, and was weighted immediately. The percentage of a water adsorption $\left(\mathrm{W}_{\mathrm{sW}}\right)$ was calculated from the equation:

$$
W_{s w}=\frac{W_{30}-W_{0}}{W_{0}} \times 100
$$

Where- $W_{30}$ represents the weight of the starch film after 30 minutes of sorption and $\mathrm{W}_{0}$ is the initial weight of the starch film.

Solubility of starch films: The film solubility was determined according to Bourtoom and Chinnah [24] and expressed as the percentage of film's dry matter solubilized after immersion in water for 24 hours at $25^{\circ} \mathrm{C}$. The experiment was performed under slow agitation and the value of solubility was calculated from the following equation:

$$
S=\frac{W_{t i}-W_{t f}}{W_{t i}}
$$

Where- $\mathrm{W}_{t i}$ is the initial weight of starch film and $\mathrm{W}_{t f}$ is the weight of film after immersion.

\section{Evaluation of mechanical properties of starch-based films}

Mechanical property: The mechanical property of starch-based film was determined according to the method recommended by Parra et al. [25]. All film specimens used for the mechanical tests were preconditioned for $48 \mathrm{hr}$ at $25^{\circ} \mathrm{C}$ and $52.8 \% \mathrm{RH}$ inside desiccators containing saturated solutions of magnesium nitrate. To avoid a postaging impact on the films, those of 3 days old were used for evaluation.

Mechanical properties including tensile strength, elongation and young's modulus were performed using a texture analyzer (Model TA-500 PLUS, LLOYDЖ instrument, 2003, England). Uniform film specimens of $100 \mathrm{~mm}$ by $5 \mathrm{~mm}$ size were prepared from the starchbased film samples. The film strips were placed in the pneumatic grips of the texture analyzer, which were set at initial separation of $50 \mathrm{~mm}$. The crosshead speed was set at $50 \mathrm{~mm} \mathrm{~min}$. Values were reported as the means of triplicate determination.

Thickness of films: A micrometer was used to measure the film thickness to the nearest 0.02 and $0.04 \mathrm{~mm}$. The film thickness was used for calculation of tensile and punctures strengths. For tensile tests, the mean of two measurements across each film specimen was used. For puncture tests, the mean was calculated from 10 random measurements made across each film. And also it was used to evaluate the inhibition effect of the film at different thicknesses.

Assessment on effectiveness of antimicrobial activity of starchbased films

Antibacterial activity test on films: The microbial analyses were undertaken according to procedure recommended by Maizura et al 
[26]. The bacterial culture was grown on nutrient agar slants and kept at $4^{\circ} \mathrm{C}$. Antibacterial activity test on films was carried out using the agar diffusion method described by Maizura et al. [26]. The zone of inhibition assay on solid media was used for determination of the antibacterial effects of films against selected microorganism groups (Escherichia coli O157:H7, Salmonella typhi and Entrobacter erogenous) of strains commonly occurring in various kinds of food products typical spoilage. Mueller Hinton agar was seeded with $0.2 \mathrm{ml}$ of inoculums containing approximately 105-106 colony forming unites per milliliter $(\mathrm{CFU} / \mathrm{ml})$ of tested bacteria. The films were cut into $6 \mathrm{~mm}$ diameter discs and then placed on Mueller Hinton agar plates. The plates were incubated at $37^{\circ} \mathrm{C}$ for $24 \mathrm{hrs}$ and then after examined for 'zone of inhibition' on the film discs by using a digital reader. The antibacterial activity testing processes were undertaken at the quality and standards authority of Ethiopia, ISO accredited microbiology laboratory. If yes, then there is a need of conducting sterility test. Principally, before conducting antimicrobial activity test on films, sterilization procedure of the films was carried out to avoid cross contaminations.

\section{Statistical analyses}

Data analysis was performed using SPSS software, version 17. The General Linear Models (GLM) procedure was used for analysis of variance, used to test the effect of the thickness and saponins concentrations on the mechanical property of the film and the effect of starch and saponins films on the inhibition effect of selected microorganisms. Significance was defined at $\mathrm{p} \leq 0.05$.

\section{Results and Discussion}

\section{Proximate composition of taro}

The composition of raw taro was presented in table 2; the results showed that taro contains relatively high moisture content with a small amount of fat, protein, fiber and ash. The amount of total carbohydrates present the raw form is relatively higher than the other root crops.

The moisture content in the raw taro was $67.62 \%$ (Table 2). The maximum moisture content prescribed for safe storage by most of the taro producing countries is $13 \%$. It should be pointed out that post harvest handling methods used starting from harvesting time up to converting it in to another product. The high levels of moisture can lead to microbial damage and subsequent deterioration in quality. Climatic factors also play a part in deciding on the moisture content. The result can be explained on the basis of higher granularity due to lower granule size during the dry season illustrating the effect of environment on the moisture content.

The formation of the starch-lipid or starch-surfactant complexes improves the textural properties of various foods. The fat content of the raw taro as can be seen in table 2 was $0.41 \%$. Fat content was influenced by various pretreatments of the tubers. Since the raw taro contain much smaller quantities of native lipids, and the addition of lipids or surfactants has a strong effect on the starch properties and quality improvement. The total crude fiber in raw taro was found to be $0.72 \%$ (Table 2). The fiber content in taro varies to a great extent depending on the sieve used for removal of the fibrous material, varietal variation and age of the crop, where the fiber content increases with the maturity.

The protein content in raw taro was $2.41 \%$ which was a small amount as compared the other starches. On the other hand, a high content of protein helps have a good granular improvement by interaction with the starch. In other way the presence of small amount of protein incorporated with the starch reduces. The amount of total carbohydrates present on the raw taro was $24.9 \%$, and this value showed that taro contained a higher amount of total carbohydrates than the other components. Furthermore, the ash content of taro was $4.42 \%$ and this indicates that taro contains good amount of minerals.

\section{Physicochemical properties of starch}

The starch was extracted from the taro by using alkaline extraction procedure. This method helped to remove or eliminate the mucilage which is found inside the taro. The mucilage had a brown color and a bad odor so that it can affect the quality of the starch. In this study, the dried material obtained from the result referred to as a starch, even though the material was not completely pure. The dry matter recovered after wet milling contained very miner amount of protein, fiber and other residues.

Pasting clarity of taro starch: The pasting clarity of the starch was determined at various $\mathrm{pH}$ and constant temperature using a spectrophotometer to determine the transmittance. The results given in table 3 showed that differences in the pasting clarity depend on the media. It should be pointed out that other factors, such as amylose, lipid and protein contents, botanical source, particle size of granules, total solids concentration, degree of granule dispersion, and the capacity of granules to form aggregates might have also influenced the clarity Craig et al. [27].

Pasting properties: The pasting property of the taro starch was studied by measuring changes in its viscosity at different temperature. The pasting property of the taro starch increases as the temperature increases as shown in table 4 . The taro starch had a small granule size, which also led the higher swelling power and subsequently to the high viscosity. On the other hand, the viscosity of the paste obtained in this study decreased substantially afterwards, likely due to lower protein content and free leaching of amylose and amylopectin from the granules.

Solubility and swelling of taro starch: The solubility of the starch was determined at different temperatures as shown in table

\begin{tabular}{|c|c|c|c|c|c|}
\hline \multicolumn{7}{|c|}{ Components } \\
\hline $\begin{array}{c}\text { Moisture } \\
(\%)\end{array}$ & $\begin{array}{c}\text { Crude } \\
\text { Protein (\%) }\end{array}$ & $\begin{array}{c}\text { Crude fiber } \\
(\%)\end{array}$ & Fat (\%) & $\begin{array}{c}\text { Total ash } \\
(\%)\end{array}$ & $\begin{array}{c}\text { Total } \\
\text { Carbohydrates (\%) }\end{array}$ \\
\hline 67.62 & 2.11 & 0.72 & 0.41 & 4.24 & 24.9 \\
\hline
\end{tabular}

Table 2: Proximate composition of raw taro

\begin{tabular}{|c|c|c|}
\hline $\mathbf{p H}$ & Temperature $\left.^{\circ}{ }^{\circ} \mathbf{C}\right)$ & Pasting clarity (\%) \\
\hline 3.5 & 70 & 65.62 \\
\hline 7.0 & 70 & 66.33 \\
\hline 10.7 & 70 & 72.92 \\
\hline
\end{tabular}

Table 3: Pasting clarity and property of taro starch.

\begin{tabular}{|c|c|}
\hline Temperature $\left({ }^{\circ} \mathbf{C}\right)$ & Pasting property $\left(\mathbf{N s m}^{-2}\right)$ \\
\hline 45 & 81.40 \\
\hline 50 & 86.00 \\
\hline 55 & 90.01 \\
\hline
\end{tabular}

Table 4: Pasting property.

\begin{tabular}{|c|c|c|}
\hline Temperature $\left({ }^{\circ} \mathbf{C}\right)$ & Solubility (\%) & Swelling power (\%) \\
\hline 40 & 2.24 & 28 \\
\hline 50 & 2.35 & 50 \\
\hline 60 & 2.57 & 90 \\
\hline 70 & 2.69 & 120 \\
\hline
\end{tabular}

Table 5: Solubility and swelling power of taro starch. 
5. The Solubility increased with a temperature increase from 40 to $70^{\circ} \mathrm{C}$. Swelling power of the taro starch showed similar pattern as the solubility of the starch affected botanical source and variety.

The differences in the solubility resulted from differences in a structure of starches and they could be attributed to different chain length water through a hydrogen bond. After gelatinization these hydrogen bonds between starch molecules were broken and were replaced by the hydrogen bonds with water. The amylose content and proportion of the outside-chains of amylopectin are thought to be the major players in the water retention capacity of gel. The solubility of starch was observed to be a function of temperature between $40-70^{\circ} \mathrm{C}$.

Below the gelatinization temperature all starches (native or modified) were less soluble. The high solubility of the pre-gelatinized starches at lower temperature may be attributed to the loss of a granular structure. The release of amylose fraction of the starch as the amylose molecules are preferentially solubilized and leached from swollen starch granules. The loss of a granular structure, however, renders the starch less viscous. The swelling power of the taro starch is shown in table 5. The swelling power of taro starch increased steadily with a temperature rise from 40 to $70^{\circ} \mathrm{C}$. It becomes rapid only after the temperature reached the onset of the gelatinization temperature.

The swelling power of the starch is often related to their protein and starch contents. High protein content may cause the starch granules to be embedded within a stiff protein matrix, which subsequently limits the access of the starch to water and restricts the swelling power. The obtained results fitted these previous observations with the higher starch content having a higher swelling ability. The swelling was a function of temperature; it followed a pattern similar to that of the solubility characteristics. The higher swelling indicated a lowering of associative force between the granules and hence, the starch appears to undergo some reduction in associative forces due to oxidation. The oxidizing agent has also been claimed to penetrate deeply into the granule, acting mainly on the amorphous region.

Prior to a gelatinization, there was some increase in swelling capacity of starches. At a higher temperature $\left(60\right.$ and $\left.70^{\circ} \mathrm{C}\right)$, the starch had higher swelling. These trends may be related to the changes in surface characteristics of the starch granules. At higher temperatures the starch granules lost their structure and this resulted in a low swelling capacity. Continuous heating increased the mobility and collision of the swollen granules and amylase molecules.

In addition to protein content, a high concentration of ash may increase a hydration and the swelling power by weakening the extent of bonding within the crystalline domain. The taro starch contains a high amount of starch relative to from other tuber root crops which is the amylopectin primarily responsible for granule swelling. According to the research finding of Forssel et al. [28], higher amylose content reduced the swelling factor of the starch.

\section{Properties of starch based-films}

Moisture content: The moisture content in the film decreased when the saponins were incorporated with the film as compared to the control film which was formed without antimicrobial agents. Saponins are a high molecular weight of carbohydrate, and this might be lead to the increase in the crystalline phase of a semi-crystalline material which was highly related to or associated with the decrease in its moisture content (Figure 1). Consequently, the increase in the crystalline fraction observed with the addition of antimicrobial. Perhaps moisture or water molecules are used as the carrier to diffuse out the antimicrobial substances from the film matrices to obtain the inhibition action [29]. The percentages of the moisture content decrease for the film with the increase the amount of antimicrobial activity [30]. The result revealed that films $\left(\mathrm{Sf}_{4}, \mathrm{Sf}_{5}, \mathrm{Sf}_{9}\right.$ and $\left.\mathrm{Sf}_{10}\right)$ had lower amount of moisture content compared to other films.

Transparency: The percentage of transmittance of taro starch film at a wavelength of $600 \mathrm{~nm}$ and containing saponins prepared by solvent casting process. The results showed (Figure 2) that the films were offwhite in color but highly translucent. Addition of saponins increased film cloudiness for starch-based films. This was due to the saponins being cloudy than the taro starch. This was attributed to starch films being inherently cloudier than starch-based composite films with no saponins added. The decrease in transparency values were observed due to the saponins incorporation. Comparing this, with the same amount of saponins, the results pointed out those films with 0.02 film thicknesses showed higher transparency values. Transparency of the films is of importance in some instances, when used as packaging materials. Addition of saponins generally causes the films to reduce their transparency. Starch composite film without saponins was rather transparent. However, a lower transparency of the films was noticed when a greater amount of saponins were incorporated.

Swelling and solubility of starch-based films: Starch, being a hydrophilic polymer, shows high affinity towards water. Hence, upon hydration, starch-films absorb water and swell. The swelling behavior of plasticized starch based film formed with saponins is showed in figure 3 . The film with a small amount of saponins content had a greater swelling capacity than the films with high saponins concentrations.

Therefore, films which had various ratios of starch and saponins showed a lower swelling power 2203 and $2110 \%$ for $\mathrm{Sf}_{9}$ and $\mathrm{Sf}_{10}$;

\begin{tabular}{|c|c|c|c|c|c|}
\hline Film type & Thickness(mm) & Saponin(w/w) & Tensile strength (MPa) & Elongation (\%) & Young's modulus (MPa) \\
\hline Control $_{1}$ & 0.02 & 0 & 24.10 & 89.02 & 4874 \\
\hline $\mathrm{Sf}_{1}$ & 0.02 & 2 & 24.92 & 72.66 & 5021 \\
\hline $\mathrm{Sf}_{2}$ & 0.02 & 4 & 25.15 & 54.90 & 5372 \\
\hline $\mathrm{Sf}_{3}$ & 0.02 & 6 & 26.72 & 47.84 & 5491 \\
\hline $\mathrm{Sf}_{4}$ & 0.02 & 8 & 28.05 & 40.65 & 5580 \\
\hline $\mathrm{Sf}_{5}$ & 0.02 & 10 & 28.20 & 29.77 & 5720 \\
\hline Control $_{2}$ & 0.04 & 0 & 23.99 & 92.74 & 4981 \\
\hline $\mathrm{Sf}_{6}$ & 0.04 & 2 & 24.84 & 85.21 & 5100 \\
\hline $\mathrm{Sf}_{7}$ & 0.04 & 4 & 25.07 & 71.00 & 5310 \\
\hline $\mathrm{Sf}_{8}$ & 0.04 & 6 & 26.63 & 66.50 & 5637 \\
\hline $\mathrm{Sf}_{9}$ & 0.04 & 8 & 28.11 & 37.68 & 5683 \\
\hline $\mathrm{Sf}_{10}$ & 0.04 & 10 & 28.18 & 30.70 & 5724 \\
\hline
\end{tabular}

Table 6: Mechanical properties of starch-based film. 


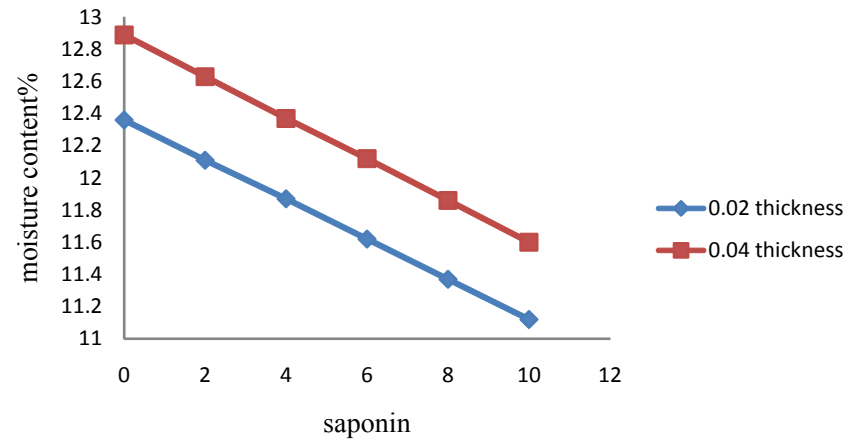

Figure 1: Moisture content of 0.02 and $0.04 \mathrm{~mm}$ thickness films.

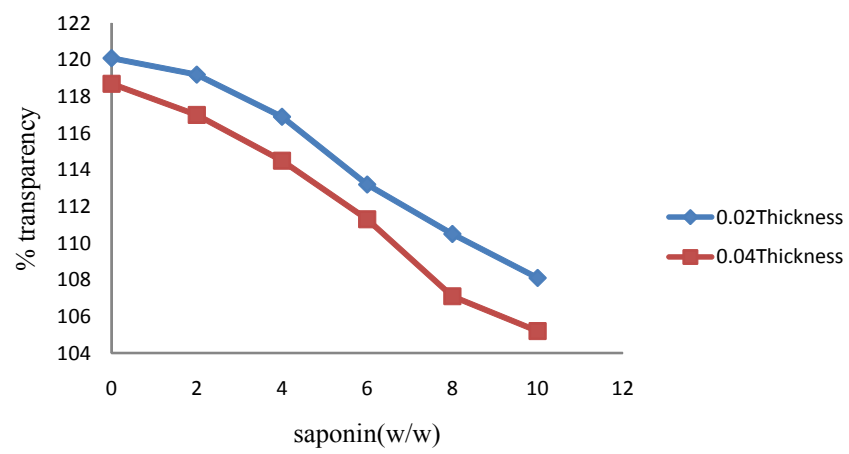

Figure 2: Transparency of starch-based film for 0.02 and $0.04 \mathrm{~mm}$ film thickness.

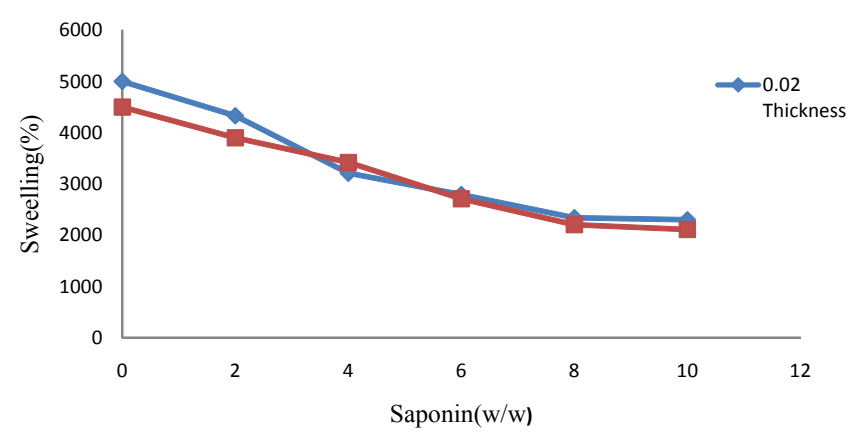

Figure 3: Swelling of the film for 0.02 and $0.04 \mathrm{~mm}$ thickness.

respectively, and can recommended for packaging purposes. The film which has ability to dissolve in water may be a good candidate for edible film and packaging material development which in turn requires complete solubility upon hydration process. Films which revealed an extremely high swelling power (Control ${ }_{1} \mathrm{Control}_{2}, \mathrm{Sf}_{1}$ and $\mathrm{Sf}_{6}$ ) may be desirable for development of absorbent pads such as those used in meat packages to absorb exudates from meat.

The solubility of the films was influenced by the amount of the saponins used in each of them. As can be seen in figure 4 the films containing a small amount of the saponins had a higher solubility. On the other the films containing a larger amount of saponins had a lower solubility. The control films had the highest solubility (1.34\%) than all the other starch based-films. Based on results it can be recommended that films having a low solubility are favorable for the packaging purpose.

Mechanical properties of films: Knowledge of mechanical properties of films is necessary for packaging materials to ensure its integrity and content. Developing edible films with mechanical properties comparable, or superior, to those of synthetic packaging materials has been a challenge. Mechanical properties of the films were evaluated in terms of a tensile strength, (\% elongation) and Young's modulus values which was related to structural characteristics of the films.

The determination of mechanical properties involves not only scientific but also technological and practical aspects [31].Thus, the mechanical properties of the films were studied to determine the values of important parameters such as tensile strength (TS), Young's modulus (Y), and percent of elongation (E).

Starch by itself is brittle and could not form a flexible material. Most biopolymers are brittle in nature with lower tensile strength, E (\%) and Young's modulus values. Addition of plasticizers to biopolymer relieves their brittleness and makes them tougher. The values of the tensile strength of the films which were made from various ratios of saponins to starch were shown in table 6 . The tensile strength of the film with incorporated saponins was much higher than that of pure starch film. The results showed that the addition of the saponins improved the mechanical properties of the material. When the saponins were added into the starch solution, there was a gradual increase in both the tensile strength and the Young's modulus (Table 6). The significant increment in the tensile strength of the film with the incorporated saponins indicated the presence of intermolecular interactions in the films. Consequently, the Young's modulus value was $5720 \mathrm{MPa}$ at the maximum content of saponins used.

The percentage elongation (E) values of the film with the incorporated saponins were the measure of a flexibility of the film and were affected by the starch to saponins ratios. An increase in the percentage elongation with an increase in starch content is due to the reduction in the number of intermolecular cross-links and increase in the inter-molecular distance. Structurally, starch contains amylopectin which is a branched polymer. As a result, the incorporation of saponins into the starch-based film led to improvement in both tensile strength and Young's modulus due the reinforcement effect.

\section{Effect of film composition on antimicrobial activity of starch- based films}

In tests conducted for E. coli, salmonella and Entrobacter a small zone formation was observed around the starch control films. On

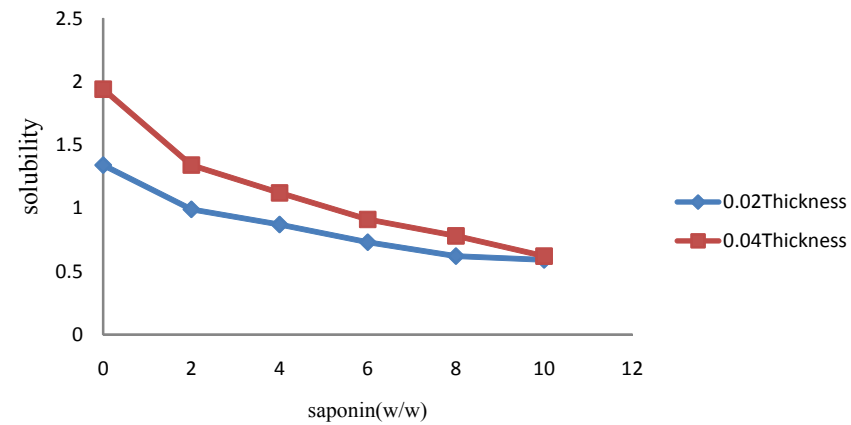

Figure 4: Solubility of the film for 0.02 and $0.04 \mathrm{~mm}$ thickness of films. 
the other hand, clear zones surrounding most of the films containing combination of saponins and starch were measured. This result simply indicated diffusion of antimicrobials from the films and a subsequent growth inhibition of the selected microorganisms in the medium.

Among the starch-based films studied, all films containing saponins exhibited a major inhibitory effect on all the three bacteria's. All films showed the typical inhibition zones against the bacteria tested and zones were considerably thicker in the antimicrobial starch films than those produced by starch control films. Also, the inhibitory effects of films were remarkably higher for E. coli and Salmonella as indicated by thicker inhibition zones accounting for more than $4 \mathrm{~mm}$.

The higher inhibitory activity shown by all antimicrobial films can be attributable to complete solubility of saponins which could make them more reactive against bacterial cells [32]. The total area of the fully formed zones, hence, the antimicrobial activities of the films, increased with increased saponins content in the film forming solution. In addition, when the thicker surfaces instead of lighter surfaces were brought into contact with the agar medium, the antimicrobial activities increased. In fact, this was an expected result since the thicker films with a 0.04 thickness films gave a higher soluble saponins activity during the release tests. On the other hand, a limited diffusion of the antimicrobial agents' films with lighter thickness at $0.02 \mathrm{~mm}$ caused the formation of less clear zones.

All 12 samples used in the test produced the clear zones around the antimicrobial films for both E. coli, Salmonella typhi. For Entrobacter erogenous, ten of the samples used in the test produced fully formed clear zones formed when their surfaces were brought into contact with the bacteria and two of the samples (control 1 and control 2)

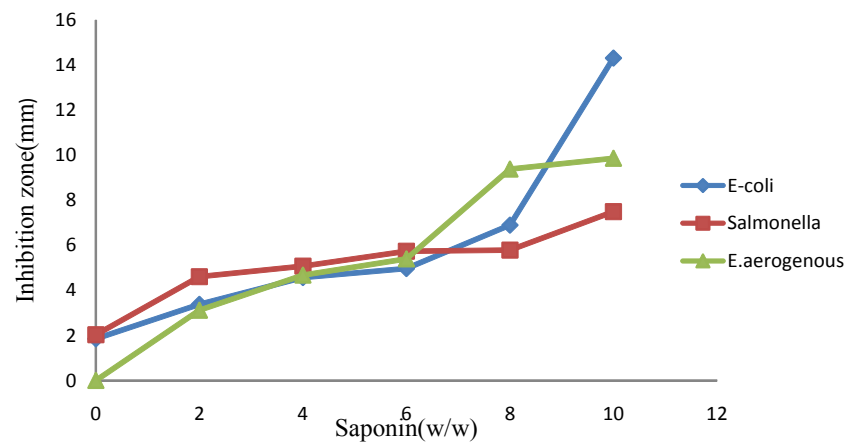

Figure 5: Zone of inhibition on agar plate test for $0.02 \mathrm{~mm}$ film thickness.

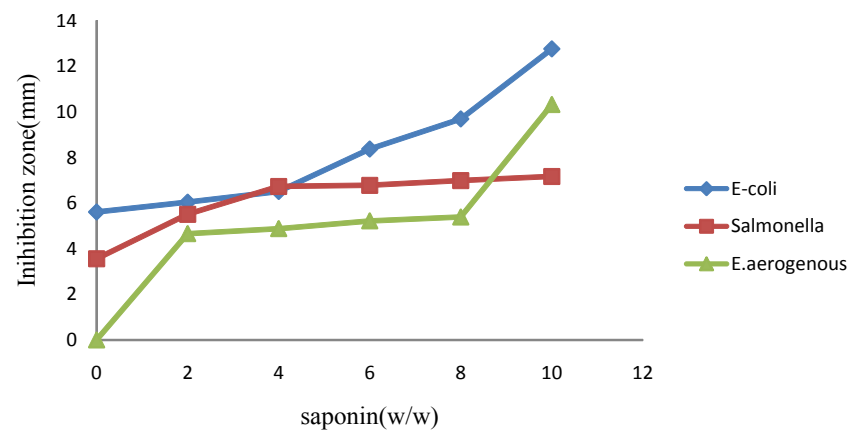

Figure 6: Zone of inhibition on agar plate test for $0.04 \mathrm{~mm}$ film thickness. used showed no inhibition effect. The results shown in figure 5 and 6 clearly suggest that the antimicrobial activity of saponins against $\mathrm{G}(-)$ bacteria, E.coli, salmonella and Entrobacter erogenous can be controlled by changing the composition of the casting solution.

Inhibition of E.coli on agar plate test: The inhibitory activity was measured based on the average diameter of the clear inhibition zone. If there was no clear zone surrounding, it was assumed that there was no inhibitory effect. After $24 \mathrm{hrs}$ incubation at $37^{\circ} \mathrm{C}$ for the starch film which was blended with different amount of saponins $\left(\mathrm{S}_{\mathrm{f}}\right)$, there was a very clear inhibition which occurred for all Salmonella, E. coli and Entrobacter erogenous. On the contrary, the films without saponins (bioactive component) film (control), showed a very small inhibition for all salmonella and E. coli. However, the effect was not as good as combination of bioactive component and starch.

Starch and bioactive component containing a higher amount of bioactive component concentrations $(6-10 \% \mathrm{w} / \mathrm{w})$, revealed the best inhibition on E. coli which is Gram-positive bacteria compared to other starch-saponins ratios ranges from $0-4 \%$ by weight. The results indicated that saponins-starch ratio $90 / 10$ and $92 / 8$ was the best formulation to inhibit $E$. coli effectively followed by a starch to saponins ratio $92 / 8$ where more effective towards inhibition of $E$. coli. The antimicrobial effectiveness of saponins-starch composite films against $E$. coli increased with an increase in the saponins concentration in the film. The films made with different saponins concentration showed a significant $(\mathrm{p}<0.05)$ difference in inhibition of $E$. coli.

For $0.02 \mathrm{~mm}$ thickness films the inhibition of E. coli increased with the saponins concentration from $0-10 \%$ and it showed a highest inhibition effect as compared to Salmonella typhi and E. erogenous. Alternatively films with 0.04 thicknesses showed a highest inhibition effect in saponins concentration of $4-10 \%$.

Inhibition of salmonella on agar plate test: An increase in the antimicrobial activity with an increase in a bioactive component concentration against gram-positive salmonella may indicate that bioactive component is the primary contributor of a Gram-positive bacteria inhibition. The pure starch film (control) showed the antibacterial activity against salmonella. As can be seen in figures 5 and 6 the most steady synergistic inhibition trend was observed for both $0.04 \mathrm{~mm}$ and $0.02 \mathrm{~mm}$ thickness films containing a higher amount of saponins. The results showed that, the strongest antimicrobial activity against salmonella was exhibited by films containing the highest saponins concentration.

For the $0.02 \mathrm{~mm}$ thickness films containing $4-8 \%$ saponins concentration the result showed that, the inhibition effect was closely similar. The maximum inhibition observed at the saponins concentration reached to $10 \%$. On the contrary for the 0.04 thickness films, the inhibition effect increased from $0-4 \%$ saponins concentration and the inhibition effect slightly increased as the concentration of saponins increased. Generally, these results suggested that the antimicrobial activity of taro starch can be enhanced with incorporation of saponins into starch film matrix and the ratio of starch to saponins molecules was an important factor affecting the antimicrobial mechanisms of saponins-starch composite films.

Inhibition of Entrobacter erogenous on agar plate test: There was no inhibition effect for E. erogenous, with the control film and the bacteria colonies occurred also at the top of film. This result expressed that $E$. erogenous required a large amount of saponins to inhibit its growth as compared to E-coli. As shown in figures 5 and 6 , the growth of $E$. erogenous was not effectively inhibited by the starch composite 
films containing no saponins. However, inhibition of E. erogenous was observed in the remaining films which were produced by a combination of starch and saponins at different proportion. Inhibition of $E$. erogenous observed as the amount of saponins increased.

Film with $0.04 \mathrm{~mm}$ thickness and containing $10 \%$ of bioactive component showed a higher inhibition effect in Salmonella typhi and lower in E. coli. As the saponins concentration increased from 2-8\%, similar inhibition effect also observed. Conversely for $0.02 \mathrm{~mm}$ film thickness the inhibition effects gradually increase as the bioactive component concentration increased. Diverse investigators in their findings revealed that development of biopolymers coating natural antimicrobial agents and their effective commercialization will be a great step towards attaining sustainability in food packaging applications $[33,34]$. Antimicrobials will undoubtedly continue to be needed to provide the food supply that will be demanded in the future. The future of research in the area of food antimicrobials will likely be on the expansion of information on the antimicrobial spectrum of natural antimicrobials.

\section{Conclusions}

The research finding demonstrated that a starch-based film can efficiently carry a high concentration of saponins as bioactive ingredient to develop various composite films. The films formed with the mix of starch and saponins were highly flexible and resembled plastic films. The films had a synergistic antimicrobial effect against Salmonella, E. coli and Entrobacter when saponins and starch were combined. The tensile properties of the films were significantly influenced by the ratio of starch and saponins used for formation of the films. The mechanical property of the films increased as the saponins amount increased. The results have clearly shown that a release rate of the saponins from the films can be modified by changing the composition of the initial casting solution. The maximum antimicrobial activities and tensile strength of the films boosted with an increase in amount of the saponins concentration in the casting solution.

Finally, this study confirms that taro starch and saponins extracted from Beshbesh haricot bean seeds can be used to develop antimicrobial films effective against food pathogenic bacteria (Escherichia coli, Salmonella typhi and Entrobacter erogenous) based on the clear inhibition zone exhibited. The enhanced antimicrobial activities of starch-based films can broaden the applications of these renewable natural materials in ensuring food safety and quality. Characteristically, the films may be used as foods packaging that are susceptible to microbial growth or directly used as a surface coating on perishable fruits and vegetables to enhance their microbial safety and prolong a shelf-life of value-added food products.

\section{References}

1. Seyhun G (2007) Preparation and Characterization of Antimicrobial Polymeric Films for Food Packaging Applications. School of Engineering and Science of Zmir Institute of Technology, Chemical Engineering Department.

2. Jung $\mathrm{H}$ (2003) Consider critical factors when designing antimicrobial packaging systems. Technology Intelligence, Inc. Department of Food Science, University of Manitoba, Canada.

3. Vicentini NM (2003) Preparation and characterization of edible films based on cassava starch for use post harvest. PhD Thesis, State University, Julio Mesquita Filho.

4. Kandasamy N (2005) Development and characterization of antimicrobial edible films from crawfish chitosan. Malaysia University of technology.

5. Gallo JAQ, Debeaufort F, Callegarin F, Voilley A (2000) Lipid hydrophobicity, physical state and distribution effects on the properties of emulsion-based edible films. J Membrane Sci 180: 37-46.
6. Ji Y, Seetharaman K, White PJ (2004) Optimizing a Small-Scale Corn-Starch Extraction Method for Use in the Laboratory. Am Asso Cereal Chem 81: 55-58.

7. Ida IM, Firdausi R, Lisa MS (2004) Study of an active antimicrobial system using a bio-switch concept. Project Report, Malaysia University of Technology, Malaysia.

8. Fellows $P$ (2000) Food processing technology, principle and practice. Wood head Publishing Limited and CRC Press, USA.

9. Güçlü-Ustündağ O, Mazza G (2007) Saponins: properties, applications and processing. Crit Rev Food Sci Nutr 47: 231-258.

10. Krochta J, Baldwin EA, Nisperos-Carriedo MO (1994) Edible coatings and films to improve food quality. Technomic Publishing Company Inc, Lancaster, USA

11. Fontes LCB, Ramos KK, Sivi TC, Queiroz FPC (2011) Biodegradable Edible Films from Renewable Sources-potential for their Application in Fried Foods. Am J Food Technol 42: 555-567.

12. Cuq B, Gontard N, Guilbert S(1997) Thermoplastic properties of fish myofibrilla proteins: application to bio-packaging fabrication. Polymer 38: 4071-4078.

13. Cuq B, Gontard N, Guilbert S (1995) Edible films and coatings as active layers.

14. McHugh TH, Krochta JM (1994) Water vapor permeability properties of edible whey protein-lipid emulsion films. J Am Oil Chem Soci 71: 307-312.

15. Lin SY, Chen KS, Run-Chu L (2000) Organic esters of plasticizers affecting the water absorption, adhesive property, glass transition temperature and plasticizer permanence of eudragit acrylic films. J Control Release 68: 343-350.

16. Admassu Shimelis E, Kumar Rakshit S (2005) Antinutritional factors and in vitro protein digestibility of improved haricot bean (Phaseolus vulgaris L.) varieties grown in Ethiopia. Int J Food Sci Nutr 56: 377-387.

17. Tomoko M, Naofumi M (2004) Characteristics of Java Taro Starches and Physical Properties of Acid and Heat-treated Taro Starches. J Appl Glycosci 51: 109-113.

18. AOAC (2003) Association of Official Analytical Chemists (AOAC). Officia methods of analysis of the association of official analytical chemist Food composition; additives; natural contaminants. Washington, DC.

19. Zohar K, Hilla GS, Oded Y (2005) Microwave-assisted extraction of bioactive saponins from chickpea (Cicer arietinum L). J Sci Food Agric 85: 406-412.

20. Eraricar S, Ida IM, Nozieana K (2009) Structural Characterization and Physical Properties of Antimicrobial (AM) Starch-Based Films. World Acad Sci Eng Technol 55: 432-440.

21. Ashveen VN, Randhir PC, David R, Jagjit RK (2008) Isolation and properties of starch from some local cultivars of cassava and taro in Fiji. S Pac J Nat Sci 26: $45-48$

22. Feroz A, Abid H (2009) Studies on Swelling and Solubility of Modified Starch from Taro (Colocasia esculenta). Effect of $\mathrm{pH}$ and Temperature. Agric Consp Sci 74: 45-50.

23. Finkenstadt V, Willett JL (2005) Preparation and Characterization of Electroactive Biopolymers. Special Issue: Biological and synthetic polymer networks and gels. Macromol Sym 227: 367-372

24. Bourtoom T, Chinnah MS (2009) Improvement of Water Barrier Property of Rice Starch-chitosan Composite Film Incorporated with Lipids. Food Sci Technol Int 15: 149-158.

25. Parra DF, Tadini CC, Ponce P, Lugao AB (2004) Mechanical properties and water vapor transmission in some blends of cassava starch edible films. Carbohyd Polym 58: 475-481.

26. Maizura M, Fazilah A, Norziah MH, Karim AA (2008) Antibacterial Activity of Modified Sago Starch-Alginate Based Edible Film Incorporated with Lemongrass (Cymbopogon citratus) Oil. Int Food Res J 15: 233-236.

27. Craig SAS, Maningat CC, Seib PA, Hoseney RC (1989) Starch paste clarity. Cereal Chem 66: 173-182.

28. Päivi M, Riitta P, Jukka S, Forssell P (2002) Effect of glycerol on behaviour of amylose and amylopectin films. Carbohyd Polym 50: 355-361.

29. Khairuddin N, Razi ARM, Muhamad II (2005) Study of an antimicrobial starchbased active packaging system. J Sci Technol 17: 1-7. 
Citation: Assefa Z, Admassu S (2013) Development and Characterization of Antimicrobial Packaging Films. J Food Process Technol 4: 235. doi:10.4172/2157-7110.1000235

Page 9 of 9

30. Bertuzzi MA, Armada M, Gottifredi JC (2003) Thermodynamic Analysis of Water Vapour Sorption of Edible Starch Based Films. Food Sci Technol Int 9: 115-121.

31. Freddi G, Monti P, Nagura M, Gotoh Y, Tsukada M (1997) Structure and molecular conformation of tussah silk fibroin films: Effect of heat treatment. J Polym Sci Pol Phys 35: 841-847.
32. Sunil M (2012) Antimicrobial Food Packaging to Enhance Food Safety: Current Developments and Future Challenges. J Food Process Technol 3: e103.

33. Appendini P, Hotchkiss JH (2002) Review of antimicrobial food packaging. J Innov Food Sci Emerg Technol 3: 113-126.

34. Weber CJ, Haugaard V, Festersen R, Bertelsen G (2002) Production and applications of biobased packaging materials for the food industry. Food Addit Contam 19: 172-177. 